\title{
Mechanochemical Synthesis of Crystalline and Amorphous Digold(I) Helicates Exhibiting Anion- and Phase-Switchable Luminescent Properties
}

\author{
Csaba Jobbágy, ${ }^{\mathrm{a}}$ Miklós Molnár, ${ }^{\mathrm{a}}$ Péter Baranyai ${ }^{\mathrm{b}}$ and Andrea Deák ${ }^{* \mathrm{a}}$ \\ ${ }_{5}$ Received (in $\left.X X X, X X X\right)$ Xth $X X X X X X X X X 20 X X$, Accepted Xth XXXXXXXXX 20XX \\ DOI: 10.1039/c4dt01214c
}

For the first time mechanochemical synthesis has been used for the preparation of crystalline and amorphous dinuclear $\operatorname{gold}(\mathrm{I})$ helicates, $\left[\mathrm{Au}_{2} \mathrm{~L}_{2}\right](\mathrm{X})_{2}\left(\mathrm{~L}=\right.$ xantphos; $\mathrm{X}=\mathrm{CF}_{3} \mathrm{SO}_{3}$, ${ }_{10} \mathrm{SCN}, \mathrm{BF}_{4}$ and $\mathrm{PF}_{6}$ ), that show anion- and phase-switchable luminescent properties. This solid-state approach provides strategies for developing switchable luminescent materials.

Mechanochemical synthesis involving mechanical grinding (in a mortar with a pestle or ball milling) of the reactants with minimal 15 or no added solvents represents viable green route for the preparation of novel solids. ${ }^{1}$ Recently, excellent reviews have been published on the progress of mechanochemistry. ${ }^{1 \mathrm{~d}-\mathrm{g}}$ The mechanochemical method continues to gain significance for its application to the development of novel metallosupramolecular 20 structures with desired functional properties, such as porous MOFs with gas sorption behaviour..$^{2-\mathrm{d}}$ Coordination polymers, metal complexes and metallamacrocycles have also been prepared by solvent-free and solvent-assisted mechanochemical methods. ${ }^{1,2}$ We also utilized the liquid-assisted grinding (LAG,

25 also known as solvent-drop grinding) in the construction of various dicyanoaurate-based heterometallic coordination polymers. $^{3}$ The as-obtained dicyanoaurate-based cobalt(II) compound displayed unique vapochromic behaviour, thus colour change on exposure to volatile organic compounds, as well as 30 water and ammonia vapours. ${ }^{3}$

The alteration of solid state structures or interconversion between different forms of the same material by the input of external chemical (solvents, guests, anions, etc.) or physical (thermal, optical, electrical, mechanical, etc.) stimulus can lead to 35 changes in a range of properties. ${ }^{4}$ Such stimuli-responsive functional materials with switchable properties are of great interest owing to their potential applications in optical storage and memories, mechanical sensors, displacement and deformation detectors, optoelectronic and display devices. ${ }^{4}$

40 Tuning and controlling the structure of cationic metal complexes by exchanging their extra framework anions with others of different shape and size can be a very powerful and promising strategy in realizing intriguing luminescent responses. ${ }^{5}$ This approach has received some attention only in the context of 45 MOFs and coordination polymers. ${ }^{5}$ Although, gold(I) compounds have also been reported to exhibit anion-dependent photoluminescence. ${ }^{6}$ Recently, we found that luminescence colour switching can be achieved by mechanical grinding of a digold(I) helicate, $\left[\mathrm{Au}_{2} \mathrm{~L}_{2}\right]\left(\mathrm{NO}_{3}\right)_{2}(\mathrm{~L}=$ xantphos $=9$,9-dimethyl${ }_{50} 4,5$-bis(diphenylphosphino)-xanthene). ${ }^{7}$ In this case, the grinding has dramatic effect on the photoluminescent properties by switching the blue-emitting crystalline compound into a redemitting amorphous form. ${ }^{7}$ As part of our ongoing studies of gold(I) compounds, ${ }^{3,7,8}$ herein we report a fast and efficient 55 solvent-drop assisted mechanochemical method for preparing crystalline and amorphous anion-exchanged dinuclear $\left[\mathrm{Au}_{2} \mathrm{~L}_{2}\right](\mathrm{X})_{2}\left(\mathrm{X}=\mathrm{CF}_{3} \mathrm{SO}_{3}, \mathrm{SCN}, \mathrm{BF}_{4}\right.$ and $\left.\mathrm{PF}_{6}\right)$ gold(I) helicates that show anion- and phase-dependent luminescent behaviour. Up to now, however, mechanochemicaly performed solid-state 60 anion-exchange has been never shown to be an effective means of altering the luminescent behaviour of a cationic metal compound.

The liquid-assisted mechanochemical anion-exchange reactions (Fig. 1) were carried out by ball-milling $\left[\mathrm{Au}_{2} \mathrm{~L}_{2}\right]\left(\mathrm{NO}_{3}\right)_{2}$ with $\mathrm{NaX}$ salts $\left(\mathrm{X}=\mathrm{CF}_{3} \mathrm{SO}_{3}, \mathrm{SCN}, \mathrm{BF}_{4}\right.$ and $\left.\mathrm{PF}_{6}\right)$ in a 1:2 molar ${ }_{65}$ ratio with addition of a very small amount of dichloromethane or water.

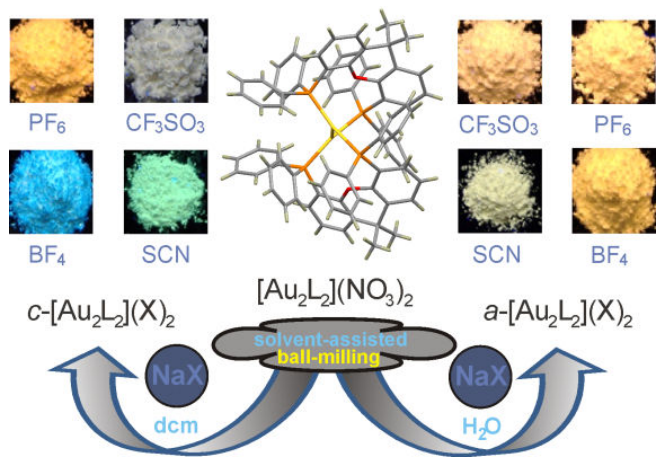

Fig. 1 Solid-state emission colours under $365 \mathrm{~nm}$ UV lamp irradiation of crystalline and amorphous $\left[\mathrm{Au}_{2} \mathrm{~L}_{2}\right](\mathrm{X})_{2}$ helicates obtained from 70 dichloromethane and water assisted grinding.

The process was monitored by FT-IR spectroscopy. Ball milling for 5 minutes was found to be sufficient for the completion of both dichloromethane and water assisted anion-exchange reactions. Both LAG reactions produced a powder mixture 75 containing anion-exchanged products $\left[\mathrm{Au}_{2} \mathrm{~L}_{2}\right](\mathrm{X})_{2}$ and $\mathrm{NaNO}_{3}$, that after thorough washing with water provided pure samples. The typical strong band associated with nitrate anion at 1344 $\mathrm{cm}^{-1}$, completely disappeared from the IR spectra of the anion- 
exchanged $\left[\mathrm{Au}_{2} \mathrm{~L}_{2}\right](\mathrm{X})_{2}$ helicates obtained from dichloromethane and water-assisted grinding. The spectra of the products show the characteristic bands associated with the exchanged-anions, such as triflate at $1257 / 1259$ and $1029 \mathrm{~cm}^{-1}$, thiocyanate at $2108 / 2099$ $5 \mathrm{~cm}^{-1}$, tetrafluoroborate at $1057 / 1052 \mathrm{~cm}^{-1}$ and hexafluorophosphate at $829 / 831 \mathrm{~cm}^{-1}$ (see ESI).

As revealed by PXRD, dichloromethane assisted ball-milling reactions afforded crystalline anion-exchanged $c$ - $\left[\mathrm{Au}_{2} \mathrm{~L}_{2}\right](\mathrm{X})_{2}$ compounds, whereas the $c-\left[\mathrm{Au}_{2} \mathrm{~L}_{2}\right]\left(\mathrm{PF}_{6}\right)_{2}$ helicate displays only

10 some crystalline character. In contrast to dichloromethane assisted anion-exchange grinding reactions, water assisted LAG afforded amorphous $a-\left[\mathrm{Au}_{2} \mathrm{~L}_{2}\right](\mathrm{X})_{2}\left(\mathrm{X}=\mathrm{CF}_{3} \mathrm{SO}_{3}, \mathrm{SCN}, \mathrm{BF}_{4}\right.$ and $\mathrm{PF}_{6}$ ) compounds (see ESI).

The anion-exchanged crystalline $c-\left[\mathrm{Au}_{2} \mathrm{~L}_{2}\right](\mathrm{X})_{2}$ helicates 15 exhibit remarkable anion-dependent luminescent behaviour. Thus, as shown in Fig. 1, the visually observed solid state luminescence colour of these $c-\left[\mathrm{Au}_{2} \mathrm{~L}_{2}\right](\mathrm{X})_{2}\left(\mathrm{X}=\mathrm{CF}_{3} \mathrm{SO}_{3}, \mathrm{SCN}\right.$, $\mathrm{BF}_{4}$ and $\mathrm{PF}_{6}$ ) complexes under $365 \mathrm{~nm} \mathrm{UV}$ lamp irradiation depending on their anions varied from blue to orange-red. Thus,

20 for tetrafluoroborate intense blue, for thiocyanate greenish, for triflate bluish-white and for hexafluorophosphate anion orangered emission was observed. Solid state emission and excitation spectra were measured for all anion-exchanged products at room temperature. The anion-exchanged crystalline compounds $c$ $25\left[\mathrm{Au}_{2} \mathrm{~L}_{2}\right]\left(\mathrm{BF}_{4}\right)_{2}, c-\left[\mathrm{Au}_{2} \mathrm{~L}_{2}\right](\mathrm{SCN})_{2}, c-\left[\mathrm{Au}_{2} \mathrm{~L}_{2}\right]\left(\mathrm{CF}_{3} \mathrm{SO}_{3}\right)_{2}$ and $c-$ $\left[\mathrm{Au}_{2} \mathrm{~L}_{2}\right]\left(\mathrm{PF}_{6}\right)_{2}$ display broad bands with emission maxima centred at 457, 508, 525 and $675 \mathrm{~nm}$, respectively (Fig. 2). The molecular structures, packing arrangements, the pattern of non-covalent interactions can be largely affected by the size and the shape of 30 the counterions which may contribute to distinctive colour variations in photoluminescence of these $\left[\mathrm{Au}_{2} \mathrm{~L}_{2}\right](\mathrm{X})_{2}$ complexes.

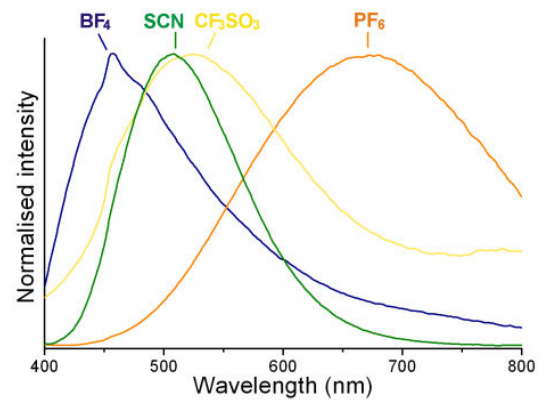

Fig. 2 Emission spectra of crystalline $c-\left[\mathrm{Au}_{2} \mathrm{~L}_{2}\right](\mathrm{X})_{2}\left(\mathrm{X}=\mathrm{CF}_{3} \mathrm{SO}_{3}, \mathrm{SCN}, \mathrm{BF}\right.$ and $\left.\mathrm{PF}_{6}\right)$ compounds obtained from dichloromethane assisted grinding.

35 The amorphous a-[ $\left[\mathrm{Au}_{2} \mathrm{~L}_{2}\right](\mathrm{X})_{2}\left(\mathrm{X}=\mathrm{CF}_{3} \mathrm{SO}_{3}, \mathrm{SCN}, \mathrm{BF}_{4}\right.$ and $\left.\mathrm{PF}_{6}\right)$ compounds show distinctly different luminescent spectra than their crystalline counterparts. Thus, as shown in Fig. 3, nearly all amorphous $a-\left[\mathrm{Au}_{2} \mathrm{~L}_{2}\right](\mathrm{X})_{2}$ helicates exhibit a common orange emission colour centred at ca. $680 \mathrm{~nm}$ upon excitation with 365

$40 \mathrm{~nm}$, but a yellowish-white luminescence with an emission maximum at $570 \mathrm{~nm}$ was observed for $a-\left[\mathrm{Au}_{2} \mathrm{~L}_{2}\right](\mathrm{SCN})_{2}$. The photoluminescence lifetimes of the crystalline and corresponding amorphous materials are nearly identical. Almost all complexes show similar biexponential decay characteristics (Table S1 in

$\left.{ }_{45} \mathrm{ESI}\right)$ but significantly smaller lifetimes were measured in case of $\left[\mathrm{Au}_{2} \mathrm{~L}_{2}\right](\mathrm{SCN})_{2}$. The slow decay of blue-emitting form of the $\left[\mathrm{Au}_{2} \mathrm{~L}_{2}\right]\left(\mathrm{NO}_{3}\right)_{2}$ complex ${ }^{7}$ has not been observed for these anionexchanged products. Moreover, these crystalline and amorphous materials have nearly identical lifetimes as the red-emitting 50 amorphous form of $\left[\mathrm{Au}_{2} \mathrm{~L}_{2}\right]\left(\mathrm{NO}_{3}\right)_{2}{ }^{7}$ It is very remarkable that these $\operatorname{digold}(\mathrm{I})$ helicates in addition to their anion-responsive luminescent behaviour also exhibit phase-dependent luminescent features.

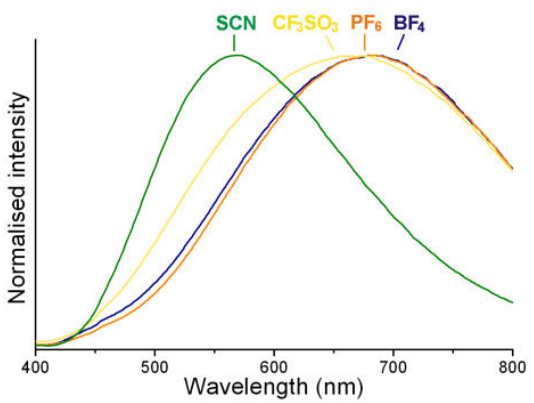

${ }_{55}$ Fig. 3 Emission spectra $\left(\lambda_{\text {ex }}=365 \mathrm{~nm}\right)$ of amorphous $a-\left[\mathrm{Au}_{2} \mathrm{~L}_{2}\right](\mathrm{X})_{2}$ compounds obtained from water assisted grinding.

Neat or liquid-assisted grinding can also induce, however, solid-state transformations, including crystalline to amorphous (CTA), ${ }^{9}$ amorphous to crystalline (ATC) ${ }^{10}$ and polymorphic ${ }_{60}$ phase changes. ${ }^{11}$ It was observed that the solvent used in LAG can control the polymorphic outcome of the mechanochemical cocrystal formation. ${ }^{12}$ Recently, we implemented the solvent-drop assisted ball-milling to perform the reversible CTA and ATC transformation of the $\left[\mathrm{Au}_{2} \mathrm{~L}_{2}\right]\left(\mathrm{NO}_{3}\right)_{2}$ helicate. $^{7}$ The as-resulting ${ }_{65} 200 \mathrm{~nm}$ shift in emission maxima was unprecedented among mechanochromic luminescent compounds. The $\left[\mathrm{Au}_{2} \mathrm{~L}_{2}\right](\mathrm{X})_{2}(\mathrm{X}=$ $\mathrm{CF}_{3} \mathrm{SO}_{3}, \mathrm{SCN}$ and $\mathrm{BF}_{4}$ ) helicates having crystalline and amorphous forms with distinct emission properties seems ideal to study their mechanochromic luminescent behavior. These 70 crystalline compounds were ball-milled in the presence of water and the transformations were monitored by PL spectroscopy. The $c$ - $\left[\mathrm{Au}_{2} \mathrm{~L}_{2}\right](\mathrm{SCN})_{2}$ complex retains its crystallinity after ballmilling for one hour. Remarkably, the crystalline $c-\left[\mathrm{Au}_{2} \mathrm{~L}_{2}\right](\mathrm{X})_{2}$ $\left(\mathrm{X}=\mathrm{CF}_{3} \mathrm{SO}_{3}\right.$ and $\left.\mathrm{BF}_{4}\right)$ helicates can be amorphized by 75 mechanical milling (Fig. S20 and S21 in ESI). To achieve the reverse ATC transformation, these amorphous samples obtained from CTA phase change were ball-milled in the presence of dichloromethane. The PL spectra showed that few minutes of ball-milling was sufficient to convert the amorphized helicates 80 into their crystalline counterparts. The $\left[\mathrm{Au}_{2} \mathrm{~L}_{2}\right]\left(\mathrm{BF}_{4}\right)_{2}$ helicate exhibits an unprecedentedly large, reversible shift of $235 \mathrm{~nm}$ between blue and orange-red emission colours in response to mechanical and solvent vapour stimuli (Fig. 4). However, the reversible luminescent colour switching of the $\left[\mathrm{Au}_{2} \mathrm{~L}_{2}\right]\left(\mathrm{CF}_{3} \mathrm{SO}_{3}\right)_{2}$ 85 helicate between bluish-white and orange-red upon subtle interplay of mechanical and chemical stimuli is also very remarkable (Fig. S19 in ESI). The crystalline $c-\left[\mathrm{Au}_{2} \mathrm{~L}_{2}\right](\mathrm{X})_{2}(\mathrm{X}=$ $\mathrm{CF}_{3} \mathrm{SO}_{3}$ and $\mathrm{BF}_{4}$ ) helicates obtained from ATC phase change display identical photophysical characteristics (Tables S2 and S3 90 in ESI) and similar powder diffraction patterns (Fig. S20 and S21 in ESI) than those obtained from dichloromethane-assisted mechanochemical reactions.

The powder diffraction patterns (see PXRD in ESI) indicate that both amorphous $a-\left[\mathrm{Au}_{2} \mathrm{~L}_{2}\right](\mathrm{X})_{2}$ helicates produced during 


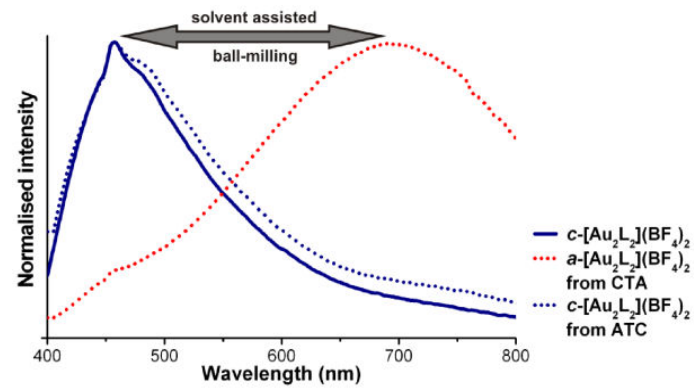

Fig. 4 Emission spectra of crystalline $c-\left[\mathrm{Au}_{2} \mathrm{~L}_{2}\right]\left(\mathrm{BF}_{4}\right)_{2}$ and amorphous $a$ $\left[\mathrm{Au}_{2} \mathrm{~L}_{2}\right]\left(\mathrm{BF}_{4}\right)_{2}$ compounds obtained from grinding induced solventassisted reversible CTA/ATC transformations.

${ }_{5}$ grinding retain some memory of original crystalline phase. This memory might be recovered through the subtle interplay between mechanical and chemical (solvent) stimuli leading to the reformation of the original crystalline order. In both cases, these reversible CTA and ATC phase changes were accompanied by 10 dramatic luminescence colour change. Finally, we note that the ability of phase change materials to switch between amorphous and crystalline states having different optical properties has already been successfully employed in rewritable optical data storage applications. ${ }^{13}$

15 Further anion-exchange reactions were performed in solution (see ESI). As revealed by PXRD, this conventional solutionbased process afforded one crystalline $c-\left[\mathrm{Au}_{2} \mathrm{~L}_{2}\right](\mathrm{SCN})_{2}$ and three amorphous $a-\left[\mathrm{Au}_{2} \mathrm{~L}_{2}\right](\mathrm{X})_{2}\left(\mathrm{X}=\mathrm{CF}_{3} \mathrm{SO}_{3}, \mathrm{BF}_{4}\right.$ and $\left.\mathrm{PF}_{6}\right)$ products. These crystalline and amorphous digold(I) helicates display 20 nearly identical powder diffraction patterns and emission characteristics (Figures S24-S35, Tables S1 and S4 in ESI) than those obtained from mechanochemical reactions.

In summary, we demonstrated that mechanochemistry is a very suitable method for performing fast and quantitative anion25 exchange of a cationic $\left[\mathrm{Au}_{2} \mathrm{~L}_{2}\right]^{2+} \operatorname{digold}(\mathrm{I})$ helicate. We have elaborated a method that depending on the nature of the grinding liquid (dichloromethane versus water) provided different solid phases (crystalline versus amorphous) of the resulting novel materials. This provides a new versatile and rapid route to 30 synthesize crystalline and amorphous states characterized by significantly different luminescent properties. Overall, the findings extend the application of grinding as a convenient method to the synthesis of novel stimuli-responsive luminescent cationic metal complexes and improve our insight into the 35 possibilities of grinding induced solvent-assisted reversible CTA/ATC transformations leading to significant luminescence responses. Currently we are investigating the influence of a series of other solvents on the formation of various solid phases of digold(I) helicates that might exhibit a range of useful properties 40 and functionalities.

We gratefully acknowledge the support from MTA Lendület Programme. The authors are indebted to Professor Gábor Pálinkás (MTA TTK) for his continuous interest and support.

\section{Notes and references}

45 a Hungarian Academy of Sciences, ${ }^{\mathrm{a}}$ MTA TTK SZKI Lendület Supramolecular Chemistry Laboratory 1117 Budapest, Magyar Tudósok körútja 2 and ${ }^{\mathrm{b}}$ MTA TTK AKI 1117 Budapest, Magyar Tudósok körútja 2, Hungary. E-mail: deak.andrea@ttk.mta.hu $\dagger$ Electronic Supplementary Information (ESI) available: Experimental 50 details, optical microscopic graphs, FT-IR spectra, emission and excitation spectra, emission, excitation characteristics and lifetimes, PXRD patterns of crystalline and amorphous $\left[\mathrm{Au}_{2} \mathrm{~L}_{2}\right](\mathrm{X})_{2}\left(\mathrm{X}=\mathrm{CF}_{3} \mathrm{SO}_{3}\right.$, $\mathrm{SCN}, \mathrm{BF}_{4}$ and $\mathrm{PF}_{6}$ ) helicates. See DOI: 10.1039/b000000x/

55 1. (a) D. Braga, F. Grepioni, Angew. Chem. Int. Ed., 2004, 43, 4002; (b) D. Braga, S. L. Giaffreda, F. Grepioni, A. Pettersen, L. Maini, M. Curzi, M. Polito, Dalton Trans.. 2006, 1249; (c) A. L. Garay, A. Pichon, S. L. James, Chem. Soc. Rev., 2007, 36, 846; (d) S. L. James, C. J. Adams, C. Bolm, D. Braga et al., Chem. Soc. Rev., 2012, 41, 413; (e) T. Friščić, Chem. Soc. Rev., 2012, 41, 3493; (f) G. A. Bowmaker, Chem. Commun., 2013, 49, 334; (g) K. D. M. Harris, Nat. Chem., 2013, 5, 12.

2. (a) T. Friščić, D. G. Reid, I. Halász, R. S. Stein, R. E. Dinnebier, M. J. Duer, Angew. Chem. Int. Ed., 2010, 49, 712; (b) W. Yuan, T. Friščić, D. Apperley, S. L. James, Angew. Chem. Int. Ed., 2010, 49, 3916; (c) T. D. Bennett, S. Cao, J. C. Tan, D. A. Keen, E. G. Bithell, P. J. Beldon, T. Friščić, A. K. Cheetham, J. Am. Chem. Soc., 2011, 133, 14546; (d) X. Ma, W. Yuan, S. E. J. Bell, S. L. James, Chem. Commun., 2014, 50, 1585; (e) A. Orita, L. Jiang, T. Nakano, N. Ma, J. Otera, Chem. Commun., 2002, 1362; (f) G. A. Bowmaker, N. Chaichit, C. Pakawatchai, B. W. Skelton, A. H. White, Dalton Trans., 2008, 2926; (g) G. A. Bowmaker, J. V. Hanna, B. W. Skelton, A. H. White, Chem. Commun., 2009, 2168.

3. Cs. Jobbágy, T. Tunyogi, G. Pálinkás, A. Deák, Inorg. Chem., 2011, 50, 7301.

4. (a) Y. Sagara, T. Kato, Nat. Chem., 2009, 1, 605. (b) 3 H. Nakayama, J.-i. Nishida, N. Takada, H. Sato, Y. Yamashita, Chem. Mater., 2012, 24, 671; (c) X. Zhang, Z. Chi, Y. Zhang, S. Liu, J. Xu, J. Mater. Chem. C., 2013, 1, 3376; (d) C. G. Schäfer, M. Gallei, J. T. Zahn, J. 80 Engelhardt, G. P. Hellmann, M. Rehahn, Chem. Mater., 2013, 25, 2309; (e) T. Mutai, H. Satou, K. Araki, Nat. Mater., 2005, 4, 685; (f) D. Yan, D. G. Evans, Mater. Horiz., 2013, 1, 46; (g) A. L. Balch, Angew. Chem. Int. Ed., 2009, 48, 2641; (h) H. Sun, S. Liu, W. Lin, K. Y. Zhang, W. Lv, X. Huang, F. Huo, H. Yang, G. Jenkins, Q. Zhao, W. Huang, Nat. Commun., 2014, 5, 3601; (i) P. K. Kundu, G. L. Olsen, V. Kiss, R. Klajn, Nat. Commun., 2014, 5, 3588.

5. (a) B. Manna, A. K. Chaudhari, B. Joarder, A. Karmakar, S. K. Ghosh, Angew. Chem. Int. Ed., 2013, 52, 998; (b) H.-Y. Wang, J.-YCheng, J.-P. Ma, Y.-B. Dong, R.-Q. Huang, Inorg. Chem. 2010, 49, 90 2416; (c) Q.-Y. Yang, K. Li, J. Luo, M. Pan, C.-Y. Su, Chem. Commun., 2011, 47, 4234.

6. (a) Balch R. L. White-Morris, M. M. Olmstead, F. Jiang, D. S. Tinti, A. L. Balch, J. Am. Chem. Soc., 2002, 124, 2327; (b) M. Osawa, I. Kawata, S. Igawa, M. Hoshino, T. Fukunaga, D. Hashizume, Chem. Eur. J., 2010, 16, 12114.

7. Cs. Jobbágy, M. Molnár, P. Baranyai, A. Hamza, G. Pálinkás and A. Deák, CrystEngComm, 2014, 16, 3192.

8. (a) A. Deák, T. Megyes, G. Tárkányi, P. Király, L. Biczók, G. Pálinkás, P. J. Stang, J. Am. Chem. Soc., 2006, 128, 12668; (b) A. Deák, T. Tunyogi, G. Tárkányi, P. Király, G. Pálinkás, CrystEngComm, 2007, 9, 640; (c) T. Tunyogi, A. Deák, G. Tárkányi, P. Király, G. Pálinkás, Inorg. Chem., 2008, 47, 2049; (d) A. Deák, T. Tunyogi, Z. Károly, Sz. Klébert, G. Pálinkás, J. Am. Chem. Soc., 2010, 132, 13627.

105 9. (a) K. J. Crowley, G. Zografi, J. Pharm. Sci. 2002, 91, 492; (b) A. R. Sheth, J. W. Lubach, E. J. Munson, F. X. Muller, D. J. W. Grant, J. Am. Chem. Soc. 2005, 127, 6641.

10. M. R. Caira, Y. Robbertse, J. J. Bergh, M. Song, M. M. De Villiers, J. Pharm. Sci. 2003, 92, 2519.

110 11. S. Ghosh, A. Mondal, M. S. R. N. Kiran, U. Ramamurty, C. M. Reddy, Cryst. Growth Des. 2013, 13, 4435-4441.

12. (a) A. V. Trask, W. D. S. Motherwell, W. Jones, Chem. Commun., 2004, 890; (b) A. V. Trask, N. Shan, W. D. S. Motherwell, W. Jones, S. Feng, R. B. H. Tan, K. J. Carpenter, Chem. Commun., 2005, 880; (c) B. D. Altheimer, S. Pagola, M. Zeller, M. A. Mehta, Cryst. Growth Des., 2013, 13, 3447.

13. (a) S. Raoux, W. Wełnic, D. Ielmini, Chem. Rev., 2010, 110, 240; (b) A. B. Cairns, A. L. Goodwin, Chem. Soc. Rev., 2013, 42, 4881. 